\title{
Optimization of Opening Roller Speed on Properties of Open End Yarn
}

\section{Abdul Salaam A Bagwan* and Abhijeet Patil}

Center for Textile Functions, Mukesh Patel School of Technology, Management and Engineering Shirpur, District-Dhule 425405, India

\begin{abstract}
An experiment conducted to spun 6's, 12's count on well-maintained open end machine by changing opening roller speed i.e., 7000 and $8000 \mathrm{rpm}$. Present investigation reveals that, as increases opening roller speed yarn properties Like Rkm, Unevenness, total IPI improved, but there is marginal improvement in U\% and RKM, and drastic reduction in total IPI, of the both yarn count. Investigation also summarized that as increases opening roller speed the cleaning intensity increases, deposition of trash in rotor groove increases leads to increase end breakages for both count. For reducing the end breakages frequency of cleaning rotors were suggested. This study also gives the difference between the properties of yarns which are produced from two different opening roller speeds. The quality parameters of the yarns produced were evaluated on an Uster Evenness Tester, the Uster Tensorapid with a testing speed of $250 \mathrm{~mm} / \mathrm{m}$ and the UT4 with a testing speed of $400 \mathrm{~m} / \mathrm{m}$.
\end{abstract}

Keywords: Opening roller speed; IPI; Uneveness; Rkm; Uster tensorapid; Uster tester

\section{Introduction}

New spinning technologies introduced in late sixties and early seventies, only rotor spinning sustained its promise and in the years to follow, it established itself as a worthy alternative to ring spinning in the course and medium count range [1-3]. The reasons for its phenomenal growth were very high productivity, around 5-8 times that of ring system, and amenability to automation and elimination of roving and winding process [3-5].

Today rotor yarns account for $30 \%$ of total spun yarn production and $23 \%$ of equivalent ring spindle installation in the world is on rotor spinning. Despite these breath taking achievements, the Indian textile industry has not responded adequately to it. The total number of rotors installed in India till date amount to less than a lac accounting for less than $2 \%$ of equivalent ring spindle installation and $10 \%$ of total spun yarn production. The yarns normally produced are $4^{\mathrm{s}}, 6^{\mathrm{s}}$ and $10^{\mathrm{s}}$ cotton yarns for end products like carpet backing,ropes, bed sheets, cycle tyre card and $7^{\mathrm{s}}, 8^{\mathrm{s}}$ and $10^{\mathrm{s}}$ for denim some of these yarns are also exported to produce cheap quality rugs. It is interesting to note that the number of rotors in India till 1984 was only 5000. This number increased significantly only after 1985 when LMW made available indigenous rotor frames at low price [6]. It is really surprising when this is contrasted with the fact that $35-40 \%$ of all yarns are spun on rotor system in USA and Europe of this $10.5 \%$ yarns are spun from acrylic, polyester in blends with cotton and viscose. The inescapable conclusion is that there is lot of scope in India to extend rotor spinning to blends and course and finer cotton yarns. Present study aimed at, Effects of opening roller speed on yarn properties for $6^{s}, 12^{s}$ count [7-9].

\section{Experimental Plan}

6's, 12's carded cotton yarn was spun at an open end machine at speed of 65000 and $105000 \mathrm{rpm}$. Trials were conducted at open-end machine by changing speed of opening roller speed $7000 \mathrm{rpm}$ and 8000 rpm on well-maintained rotor spinning machine schlafhorst Autoscore SE9288. One passage of draw frame material processed, through openend machine to determine effect opening roller speed on yarn quality in rotor spinning (Table 1). Usually imperfection, (thick, thin, neps) and short term evenness (U\%) of yarn rather than length, strength are influenced by the changes in opening roller speed, adopted for largescale working in spinning department. The mean breaking force of the yarn was measured using a standard Tensorapid tensile tester. The CV\% of the yarn mass was tested with a uster Evenness tester, to analyze the effect of opening roller speed (Figure 1).

The specification of the cotton, which was used in the study, is as follows

Effective Length - $23 \mathrm{~mm}$

Bundle Strength (gm/tex) - 23

Micronaire - $2.9 \mathrm{gm} / \mathrm{cc}$

Trash content $-6.8 \%$

Short fiber percentage -5.2

\section{Machinery details}

Make - Schlafhorst (Auto Coro)

Model - SE9 ACO 288

Made - West Germany

Year - 1998

\section{Result and Discussion}

Present investigation summarized from Tables 2-4 and Figures 2-3

\begin{tabular}{|l|c|c|}
\hline Rotor diameter & $36 \mathrm{~mm}$ & $36 \mathrm{~mm}$ \\
\hline Opening roller diameter & $60 \mathrm{~mm}$ & $60 \mathrm{~mm}$ \\
\hline Rotor speed & $65000 \mathrm{rpm}$ & $1,05,000 \mathrm{rpm}$ \\
\hline Opening roller speed & $7000 / 8000 \mathrm{rpm}$ & $7000 / 8000 \mathrm{rpm}$ \\
\hline Draft & 57.2 & 114.8 \\
\hline
\end{tabular}

Table 1: Machinery specifications.

*Corresponding author: Abdul Salaam A Bagwan, Center for Textile Functions Mukesh Patel School of Technology, Management and Engineering Shirpur, District-Dhule 425405 India, Tel: 022 4235 5555; E-mail: abdulsalaambagwan@gmail.com

Received November 02, 2015; Accepted December 23, 2015; Published January 05, 2016

Citation: Bagwan ASA, Patil A (2016) Optimization of Opening Roller Speed on Properties of Open End Yarn. J Textile Sci Eng 6: 231. doi:10.4172/21658064.1000231

Copyright: @ 2016 Bagwan ASA, et al. This is an open-access article distributed under the terms of the Creative Commons Attribution License, which permits unrestricted use, distribution, and reproduction in any medium, provided the original author and source are credited. 
that, As opening roller speed increases for courser count $\mathrm{Rkm}$ value increases and count slightly shifted toward finer side More opening, cleaning of cotton takes place due intensity of opening increases, deeply embedded trash particles associated with fibers were removed, total IPI were and unevenness were improved for both count.

\begin{tabular}{|l|c|c|}
\hline Blow room hank & 0.0012 & 0.0012 \\
\hline Carding hank & 0.100 & 0.100 \\
\hline Draw frame hank & 0.105 & 0.105 \\
\hline Open end count & $6^{\mathrm{s}}$ & $12^{\mathrm{s}}$ \\
\hline Rotor diameter & $36 \mathrm{~mm}$ & $36 \mathrm{~mm}$ \\
\hline Opening roller diameter & $60 \mathrm{~mm}$ & $60 \mathrm{~mm}$ \\
\hline Rotor speed & $65000 \mathrm{rpm}$ & $1,05,000 \mathrm{rpm}$ \\
\hline Opening roller speed & $7000 / 8000 \mathrm{rpm}$ & $7000 / 8000 \mathrm{rpm}$ \\
\hline Draft & 57.2 & 114.8 \\
\hline
\end{tabular}

Table 2: Shows hank organization and draft.

\begin{tabular}{|l|c|c|}
\hline Count & 6's & 12's \\
\hline Rotor speed & $65000 \mathrm{rpm}$ & $105000 \mathrm{rpm}$ \\
\hline Rotor type & T336 & T336 \\
\hline Sliver hank & 0.105 & 0.105 \\
\hline Draft & 57.2 & 114.8 \\
\hline TM & 5.2 & 5.3 \\
\hline TPM & 501 & 727.8 \\
\hline Package length & $31 \mathrm{Km}$ & $77 \mathrm{~km}$ \\
\hline
\end{tabular}

Table 3: Shows process parameters of the open end spinning.

Plan of work: $\quad$ Study taken for 2 different opening rollers speed.

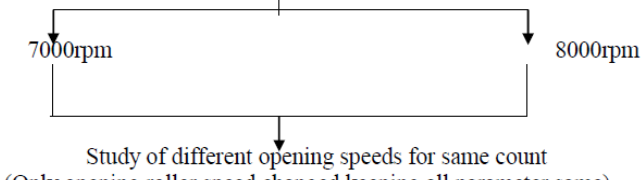

(Only opening roller speed changed keeping all parameter same)

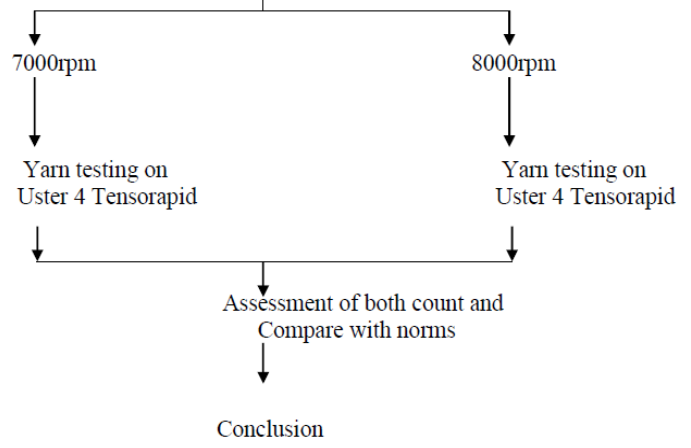

Figure 1: Experimental plan.
As the opening roller speed increases, the carrying factor (i.e., the effective number of wire points per unit time) increases, which in turn increases the opening efficiency of the opening roller. Owing to the better opening of fibres, it can be observed that, the fibre tufts of smaller size and uniform dimensions are fed into the transport tube and fibre orientation and sufficient drafting and doubling takes place in rotor groove which leads to improve $\mathrm{Rkm}$ value and reduction in unevenness and coefficient of variation of both counts (Table 2).

It was also observed during experimentation, A yarn break with a trash particle embedded end increases in the case of both yarn, because the high feed rate of fibre at the rotor groove causes the flow of trash particles to accelerate; thus, the chances of the suction tube chocking will be higher, and this will allow trash particles to go along with the fibre on the rotor surface, causing end breakages increase in open end spinning for both count (Table 3 ).

\section{Conclusions}

Present investigation summarized as follows, as opening roller speed increases from 7000 to $8000 \mathrm{rpm}$ for both count, quality parameters such as RKm value, unevenness, Total IPI improved this because of intensity of opening action and trash particles were removed. It was also noted in experiment a yarn breaks increases with a trash particle embedded in the rotor groove, because the high feed rate of fibre at the rotor groove causes the flow of trash particles to accelerate; thus,

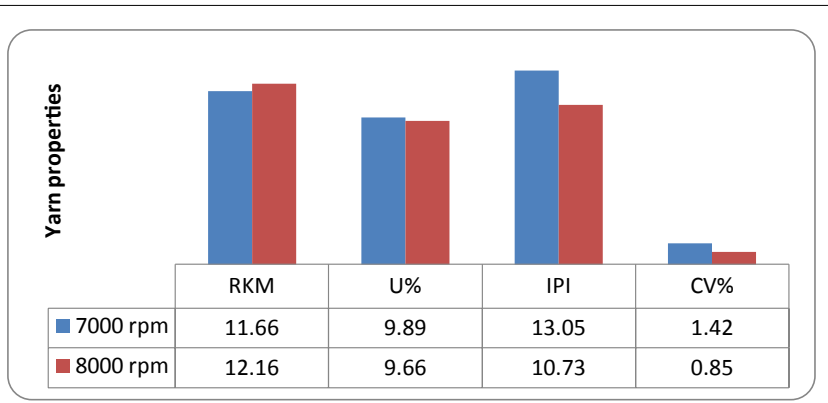

Figure 2: Effect of opening roller speed on yarn properties for 6's count

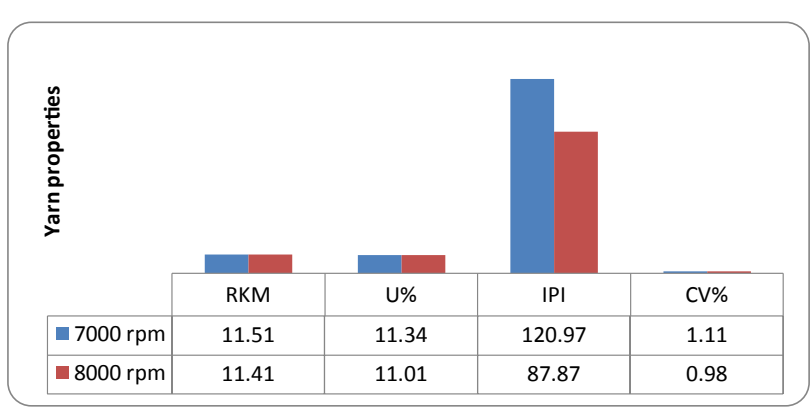

Figure 3: Effect of opening roller speed on yarn properties for 12's count.

\begin{tabular}{|c|c|c|c|c|c|c|}
\hline S.no & $\begin{array}{c}\text { Yarn parameters for } \\
\text { 6's count }\end{array}$ & $\begin{array}{c}\text { Opening speed 7000 } \\
\text { rpm }\end{array}$ & $\begin{array}{c}\text { Opening speed 8000 } \\
\text { rpm }\end{array}$ & $\begin{array}{c}\text { Yarn parameters for } \\
\text { 12's count }\end{array}$ & $\begin{array}{c}\text { Opening speed 7000 } \\
\text { rpm }\end{array}$ & $\begin{array}{c}\text { Opening speed 8000 } \\
\text { rpm }\end{array}$ \\
\hline $\mathbf{1}$ & RKM & 11.66 & 12.16 & RKM & 11.51 & 11.41 \\
\hline $\mathbf{2}$ & $\mathbf{U} \%$ & 9.89 & 9.66 & $\mathbf{U} \%$ & 11.34 & 11.01 \\
\hline $\mathbf{3}$ & $\mathbf{I P I}$ & 13.05 & 10.73 & IPI & 120.97 & 87.87 \\
\hline $\mathbf{4}$ & $\mathbf{C V} \%$ & 1.42 & 0.85 & $\mathbf{C V} \%$ & 1.11 & 0.98 \\
\hline
\end{tabular}

Table 4: Shows Yarn testing parameters for 6's and 12's count. 
Citation: BagwanASA, Patil A(2016) Optimization of Opening Roller Speed on Properties of Open End Yarn. J Textile Sci Eng 6: 231. doi:10.4172/21658064.1000231

the chances of the suction tube chocking will be higher, and this will allow trash particles to go along with the fibre on the rotor surface, causing end breakages increase in open end spinning for both count. End breakages rates reduced by the increasing the frequency of rotors cleaning.

\section{Acknowledgement}

The author thankful to Principal, Center for textile Functions MPSTME Dhule and Directors, PSSGL dye house Shirpur, District- Dhule (425405) Maharashtra - INDIA.

\section{References}

1. Barella A, Manich MA, Marinob NP, Garófalob J (1983) Factorial studies in rotor spinning of part -l: Cotton Yarns. The Journal of the Textile Institute 74: 329-339.

2. Istiaque, Sharma N (1990) Fiber disorder in open end spinning.

3. Grosberge P, Mansoor SA (1975) High speed open end rotor spinning. The Journal of the Textile Institute 66: 389-396.
4. Lord PR (1976) The Structure of Open-End Spun Yarn. Textile Research Journal 41: 778-784.

5. Barellaa A, Turaa JM, Vigoa JP, Esperona HO (1976) An application of mini-computers to the optimization of the open-end-spinning process. Part ii: Consideration of the case of three variables. The Journal of The Textile Institute 67: 325-333.

6. Salhotra KR, Balsubramanian P (1980) An approach to the optimization of rotor-spinning-machine parameters. The Journal of The Textile Institute 77 : 128-138.

7. Manohar JS, Balsubramanian N, Rakshit AK (1983) Influence of rotor speed rotor diameter and carding condition upon yarn quality in open end spinning. Textile Research Journal 53: 497-503.

8. Istiaque SM, Bhortakke (1995) Influence of fiber and machine parameters on fiber damages and reversal in rotor spinning. Asian textile journal.

9. Barellaa A,Turaa JM, Vigoa JP (1976) An application of mini-computers to the optimization of the open-end-spinning process part iii: The effect of the rotor diameter on the properties of open-end-spun yarns. The Journal of the Textile Institute 67: 421-425. 